\title{
Posterior Fixation of a Cervical Fracture Using the RRS Loop Spine System and Polyethylene Tape in an Elderly Ankylosing Spondylitis Patient: A Case Report
}

\author{
Munehisa Koizumi ${ }^{1}$, Jin lida ${ }^{1}$, Hideki Shigematsu², Nobuhisa Satoh ${ }^{3}$, Masato Tanaka', \\ Tomohiko Kura', Shinji Tsukamoto ${ }^{4}$, Yoshinobu Kato ${ }^{1}$, Yasuhito Tanaka ${ }^{1}$ \\ ${ }^{1}$ Department of Orthopaedic Surgery, Nara Medical University, Kashihara, Nara, Japan \\ ${ }^{2}$ Department of Orthopaedic Surgery, Yamatotakada Municipal Hospital, Ymatotakada, Nara, Japan \\ ${ }^{3}$ Department of Orthopaedic Surgery, Higashi-Osaka Municipal Hospital, Higashiosaka, Osaka, Japan \\ ${ }^{4}$ Department of Orthopaedic Surgery, Heisei Memorial Hosital, Kashihara, Nara, Japan
}

An 80-year-old woman presented with neck pain and paraparesis of Frankel C in her upper and lower extremities after falling. Imaging revealed an ankylosing cervical spine and a fracture line running obliquely from the anterior C3-4 to the posterior C4-5 level. Posterior fixation from the occipit to T3 was performed using the RRS Loop Spine System and concomitant polyethylene tape fixation. This system is characterized by the uniqueness of how it screws to the occipit and its use of a fixation rod with a larger diameter than in other instrumentation devices for use in the cervical region. Sublaminar banding using polyethylene tape was used to secure fixation. Her postoperative course was unremarkable, and her neck pain was relieved, although neurological improvement was minor. To our knowledge, this is the first report of an application of the RRS Loop Spine System to an ankylosing spondylitis patient with a cervical fracture.

Key Words: Ankylosing spondylitis, Cervical fracture, Instrumentation

\section{Introduction}

Ankylosing spondylosis (AS) is a well-known chronic inflammatory entity that mainly affects the axial skeleton. In Japan, the incidence of AS has been reported to be approximately $0.04 \%$ of the population [1], less than the reported prevalence in Caucasians, which is about $1 \%$ of the population [2]. Over the course of this disease, fracture is a major problem due to the combination of stiffness and osteoporosis [2,3]. The cervical spine is the main affected site for fracture, often caused by minor trauma such as falls [2]. A higher risk of concomitant neurological involvement is also a characteristic of cervical fracture in AS patients $[2,3]$. Both conservative treatment and surgery for spinal fractures in AS patients have been reported. However, each approach has drawbacks, and thus, controversy exists over the best treatment strategy [2-6]. We report the case of an elderly AS patient who sustained a cervical fracture with neurological involvement that was treated successfully by posterior fusion using the RRS Loop Spine System (DePuy Spine, Raynham, MA, USA).

\section{Case Report}

An 80-year-old woman presented with neck pain and moderate paraparesis of Frankel grade $\mathrm{C}$ after falling on stairs. A plain radiograph revealed a fracture of an ossified anterior longitudinal ligament at the C3-4 level with marked

Received Feb 21, 2011; Revised May 30, 2011; Accepted May 31, 2011

Corresponding author: Munehisa Koizumi, MD

Department of Orthopaedic Surgery, Nara Medical University,

840 Kashihara, Nara 634-8522, Japan

Tel: +81-744-22-3051, Fax: +81-744-25-6449, E-mail: mkoizumi@naramed-u.ac.jp

Copyright (C) 2012 by Korean Society of Spine Surgery

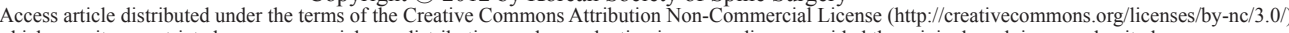
which permits unrestricted non-commercial use, distribution, and reproduction in any medium, provided the original work is properly cited. Asian Spine Journal • pISSN 1976-1902 eISSN 1976-7846 
osteoporosis of the cervical spine and ossification of each disc, making the border between the endplate and disc unclear (Fig. 1). Computed tomography showed the fracture line more clearly, indicating a fracture of the posterior longitudinal ligament at the $\mathrm{C} 4-5$ level, and an ossification mass that was encroaching on the spinal canal at the $\mathrm{C} 3$ to $\mathrm{C} 4$ level was identified (Fig. 2). A plain radiograph of the sacroiliac joint showed complete ankylosis and typical features of bamboo spine of the lumbar column that were consistent with AS. The patient's neurological status did not change despite improved cervical alignment at the fracture site and neck pain relief after Halo immobilization. These neurological deficits were a burden due to the elderly and paralytic status of this patient and caused diminished motivation and nocturnal delirium. Moreover, poor adaptation to the Halo-vest due to the patient's thoracic kyphosis and scoliosis led to a decubitus ulcer formation on her back. As a result of these conditions, surgery was selected as the treatment strategy.

The patient was set in a prone position with a Halo-vest and pillows underneath her body. The back side of the

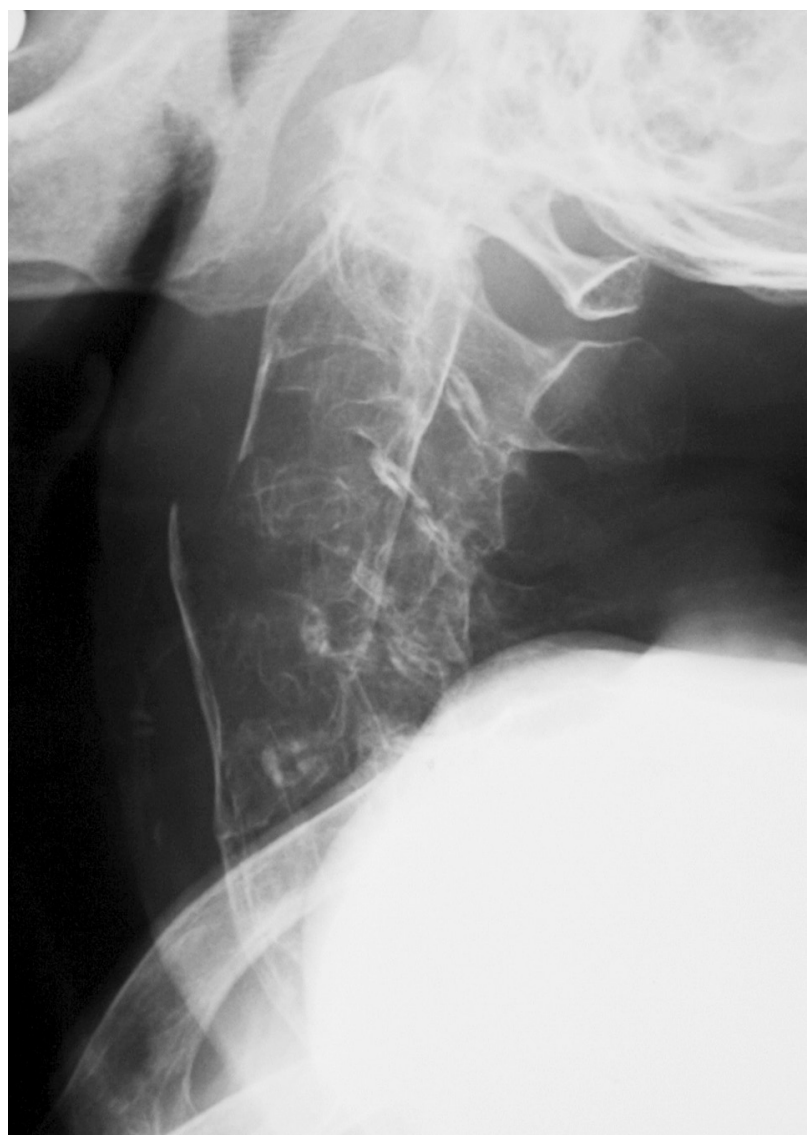

Fig. 1. A plain radiograph taken before Halo-vest immobilization shows a fracture in her cervical spine.
Halo-vest was removed temporarily to provide access for surgery. A posterior longitudinal incision was made from the external occipital protuberance to the $\mathrm{T} 3$ level. The posterior bony elements were clearly so brittle that the end of a spinal process broke merely on pinching with fingertips. The laminae of $\mathrm{C} 4$ and $\mathrm{C} 5$ had sunk between $\mathrm{C} 3$ and $\mathrm{C} 6$, but the fracture site was unclear. An RRS Loop Spine System (DePuy Spine) was applied from the immobilized occipital bone to T3. Laminar hooks were placed in the T3 lamina, and sublaminar banding using polyethylene tape (Nesplon, Alfresa Pharma, Osaka, Japan) was added at the C2, C7, and T1 laminae to secure fixation (Fig. 3). The laminae and ossified ligamentum flavum of both $\mathrm{C} 4$ and $\mathrm{C} 5$ were removed for decompression; no extradural hematoma was observed. Her postoperative course was unremarkable. The Halo-vest was removed immediately after surgery, and a cervicothoracic orthosis was fitted. Her neurological state recovered to Frankel D1, and she noticed the clumsiness in her hands was alleviated. Although neurological improvement was minor, her motivation increased, and pain from her neck and the decubitus ulcer disappeared.

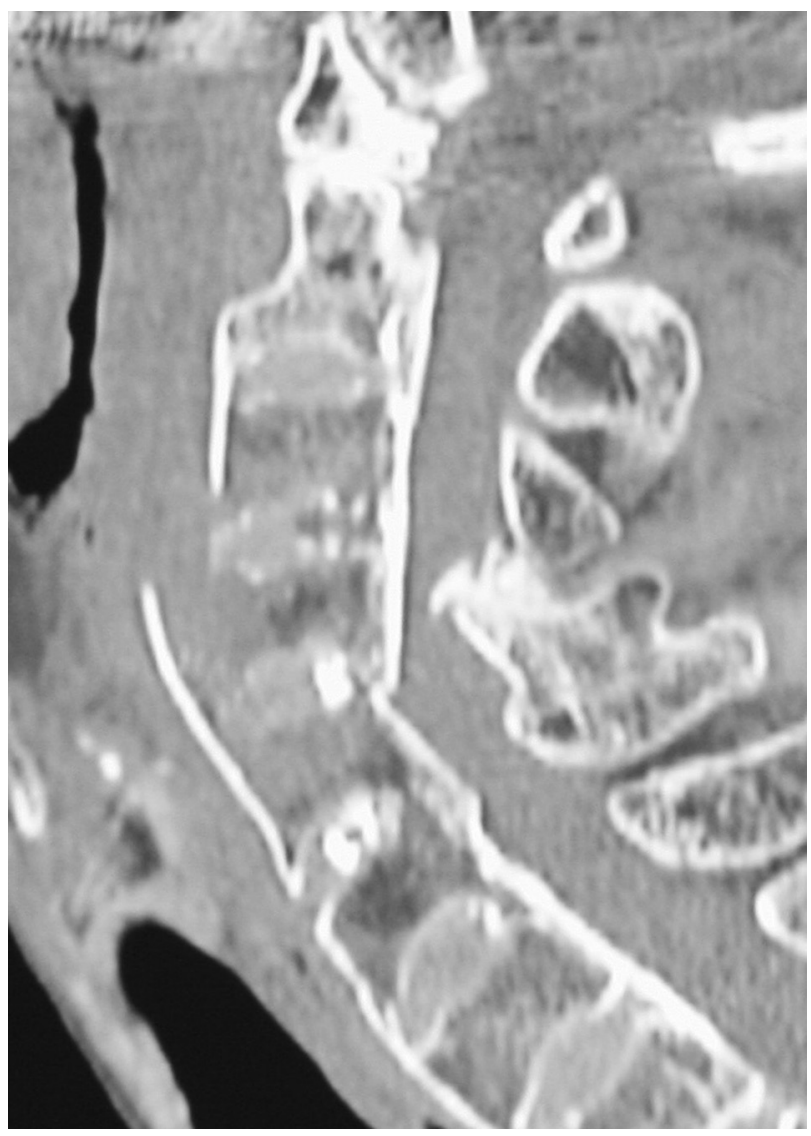

Fig. 2. Computed tomography indicates breakage of the anterior and posterior ossified longitudinal ligament and encroachment of the ossified mass in spinal canal. 
Progressive bone formation was confirmed on a plain radiograph three months after surgery (Fig. 4). She lived at the rehabilitation institute after discharge from our hospital and had no complaint of neck pain 17 months after surgery although improvement in her daily activities was limited (Fig. 5).

\section{Discussion}

The rigid spines in AS are susceptible to fractures, and the cervical spine is a major site of those injuries; furthermore, the rate of neurological involvement is high $[1,4,7,8]$. Although definite guidelines have not yet been established
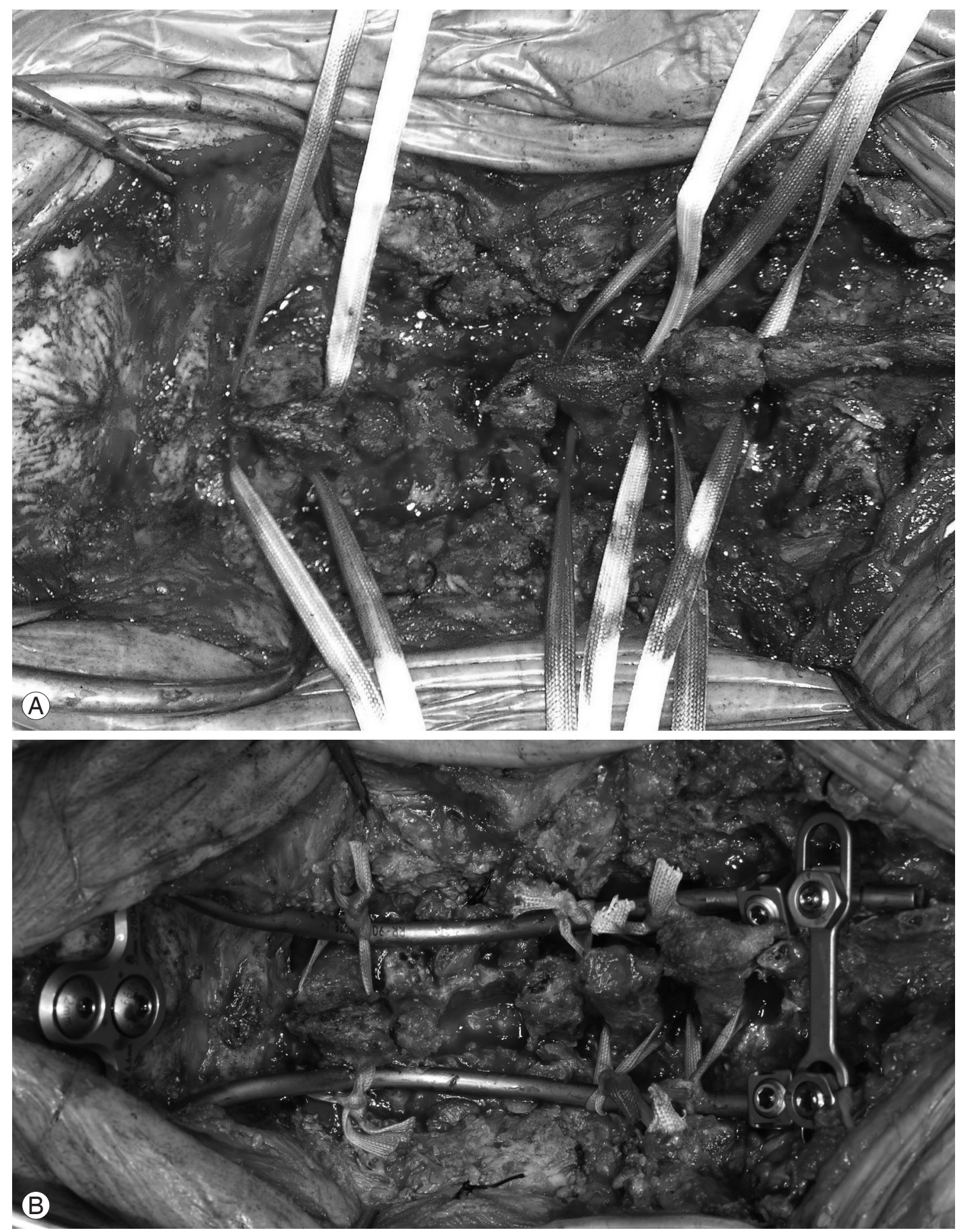

Fig. 3. (A) An intraoperative picture shows polyethylene tape passed under the laminae of C2, C7, and T1. (B) Fixation was completed with the RRS Loop Spine System and polyethylene tape. 
for the best treatment option of such fractures, reports of surgical treatment have increased while devices used in treatment have improved $[3,4,8]$. Posterior longer internal fixation with a bone graft has become mainstream using a lateral mass screw or pedicle screw system; if necessary, some surgeons also prefer concomitant anterior plating. In the current case, a fracture line ran obliquely from the anterior C3-4 level to the posterior C4-5 level and was associated with great instability. Long and rigid internal fixation was essential due to the marked osteoporosis induced by both AS and aging; however, only $\mathrm{C} 2$ and $\mathrm{C} 3$ seemed to be usable anchors on the proximal side for fixation. Additionally, the patient's small physique and relatively small bones made screw insertion difficult at the upper cervical level. Therefore, we designed a long fusion from the occipit to the upper thoracic level to achieve a rigid internal fixation. On one hand, more rigid fixation would be expected extending fixation-end to the occipit, but on the other, there is a drawback of obliterating the mobile segment at the craniovertebral junction. Additional unintended surgery seemed to be difficult in this patient when loosening or dislodgement of screws occurred, and we chose the long fusion from occipit to upper thoracic spine. The RRS Loop Spine System developed by Shimizu et al. [5] (Fig. 6) is an instrumentation device for occipitocervical or occipit-upper thoracic fixation and has a unique occipit screw that has a design inspired by the screw used to bind a snow ski to its binding. This occipit screw enables secure fixation monocortically between the occipit bone and device. The rod, $4.76 \mathrm{~mm}$ in diameter, also contributes to rigid fixation of the spinal column. In the literature, the diagnoses of patients treated with this system have been mainly rheumatoid arthritis-related disorders or unstable anomalies of the craniocervical junction $[5,6,9]$. This system could provide the solution for hyperextension injuries of the cervical spine, especially in the upper cervical region. Using the occipit as an anchor, stable fixation could be accomplished even in the case of an elderly patient or complex high-energy fracture with great instability [10]. The connection between rod and vertebra is via a pedicle screw, hook, or sublaminar wiring in a similar manner to other instrumentation devices. We selected sublaminar banding by polyethylene tape and hook placement at the lower end lamina so that the stress caused by the instrumentation would be dispersed evenly through the occipit to the upper thoracic spine in this markedly osteoporotic patient. Our
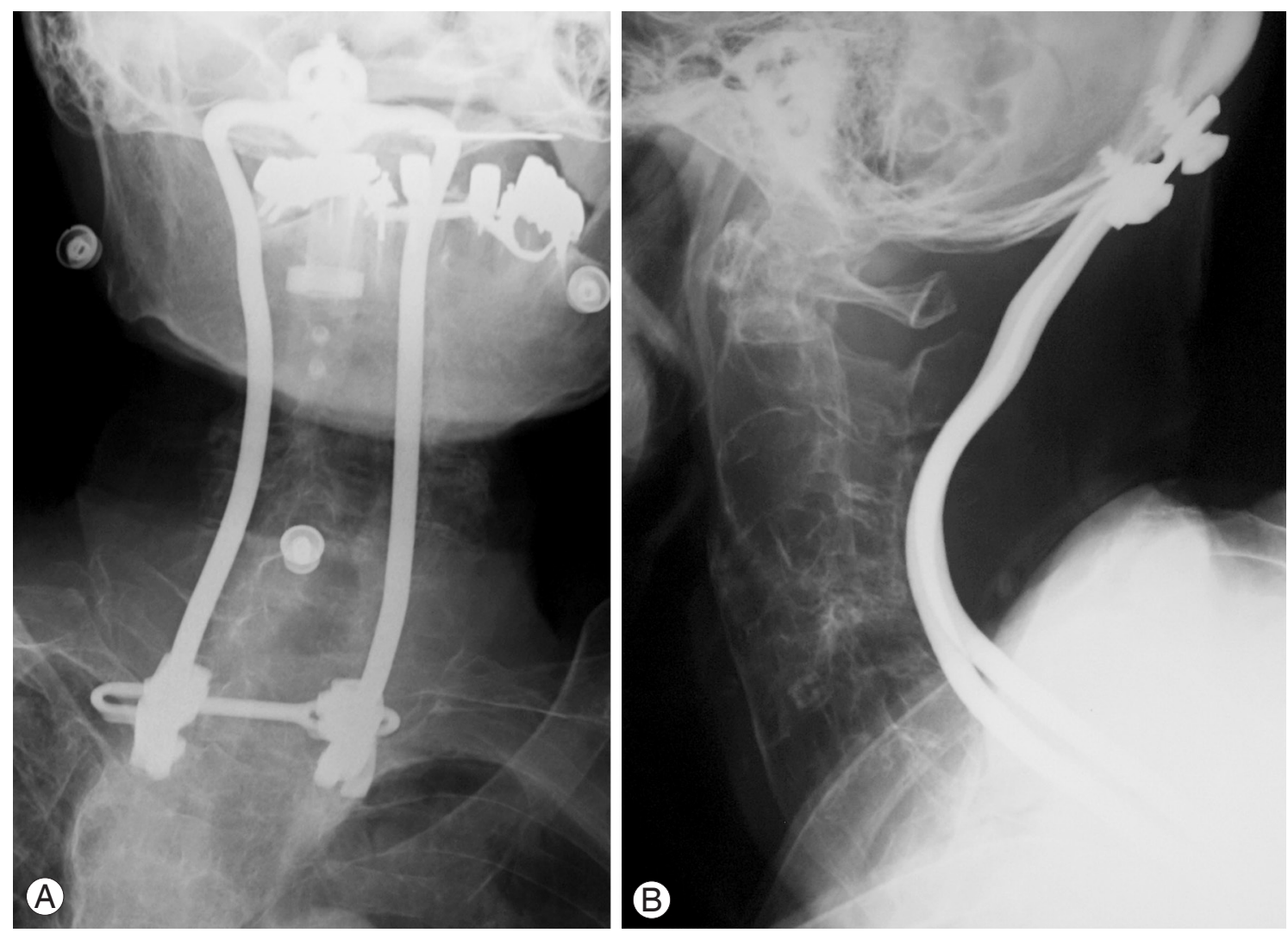

Fig. 4. A postoperative plain radiograph taken 3 months after surgery showed maintained alignment of cervical spine and progressing bone union (A, anteroposterior view; $\mathbf{B}$, lateral view). 

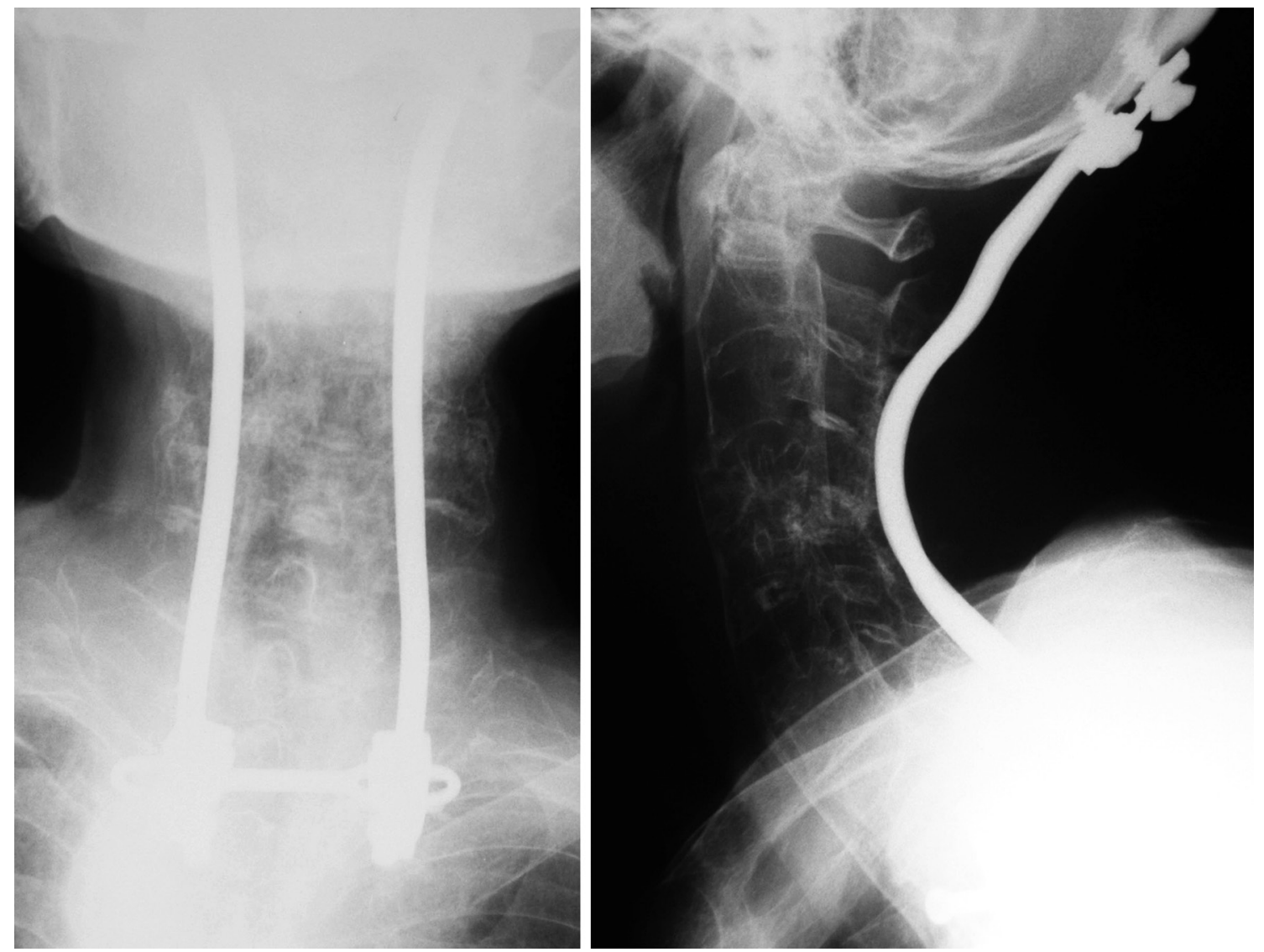

Fig. 5. RRS Loop Spine System. Picture shows rod and occipital screws.

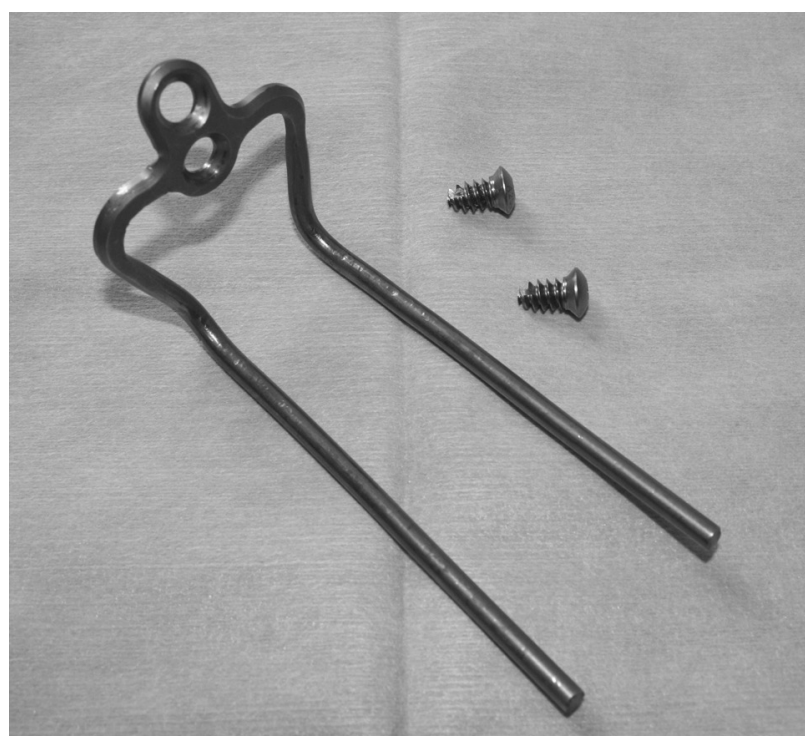

Fig. 6. Bony union and unchanged alignment as seen on a postoperative plain radiograph at 1 year.

procedure seems to be one of the surgical methods that can successfully stabilize the spinal column depending on the fracture site despite the disadvantage of fixation to the occipit bone.

\section{REFERENCES}

1. Mizuki S, Matsuda Y, Shibata Y. Management of spinal fracture in ankylosing spondylitis. Orthop Surg Traumatol 1999;42:765-71.

2. Borenstein D. Inflammatory arthritides of the spine: surgical versus nonsurgical treatment. Clin Orthop Relat Res 2006;443:208-21.

3. Braun J, Baraliakos X, Godolias G, Böhm H. Therapy of ankylosing spondylitis: a review. Part I: Conventional medical treatment and surgical therapy. Scand J Rheumatol 2005;34:97-108.

4. Taggard DA, Traynelis VC. Management of cervical spinal fractures in ankylosing spondylitis with posterior fixation. Spine (Phila Pa 1976) 2000;25:2035-9.

5. Shimizu T, Fueki K, Baba H, Ino M, Toda N, Tanouchi T. Occipito-cervical or thoracic fusion using RRS loop spinal system. J Jpn Soc Spine Surg Relat Res 2003;14:104.

6. Tagami A, Konishi H, Inatomi K, et al. Short term results of RRS loop spine system for occipitocervical 
fusion. J West Jpn Res Soc Spine 2007;33:93-6.

7. Grisolia A, Bell RL, Peltier LF. Fractures and dislocations of the spine complicating ankylosing spondylitis: a report of six cases. 1967. Clin Orthop Relat Res 2004;(422):129-34.

8. Samartzis D, Anderson DG, Shen FH. Multiple and simultaneous spine fractures in ankylosing spondylitis: case report. Spine (Phila Pa 1976) 2005;30:E711-5.
9. Yonezawa I, Tsuji T, Takahashi M, Kurosawa H. Posterior occipito-cervical or -thoracic fixation using RRS loop spinal system: a report of two cases. Jpn Spine Inst Soc 2005;4:84-7.

10. Fueki K, Shimizu T, Ino M, et al. Two elderly patients of upper cervical injuries who underwent occipitcervical fusion with RRS loop spinal system. J East Jpn Assoc Orthop Traumatol 2007;19:269. 